\title{
Principles for Incorporating Farmers in the Ethical Assessment of Genetically Modified Crops
}

This is a preprint of an article published in Ethics in Biology, Engineering and Medicine, 2010, 1(2): 83-99

(http://dl.begellhouse.com/journals/6ed509641f7324e6,2ec4c93957d0eb94,1cc5e79402da0872.html)

Jason Behrmann*

Bioethics Programs, Department of Social and Preventive Medicine, Faculty of Medicine, Université de Montréal, Montréal, Canada

\section{Bryn Williams-Jones}

Bioethics Programs, Department of Social and Preventive Medicine, Faculty of Medicine, Université de Montréal, Montréal, Canada

\section{* Corresponding Author}

Jason Behrmann

Programmes de bioéthique, Département de médecine sociale et préventive,

Université de Montréal, C.P. 6128, succursale centre-ville

Montréal (Québec) Canada H3C 3J7; E-mail: jason.behrmann@umontreal.ca

\begin{abstract}
A current advance within the agricultural industry is the use of genetic engineering to produce novel crops for food production. This technology raises questions about how societies should position themselves with respect to genetically modified (GM) crop development and implementation; namely, how should the potentials and risks of this technology be evaluated? We argue that current methods to evaluate the risks and benefits of GM crops are inadequate and not conducive to the strategic development of this technology, where a way to ameliorate technology assessments for GM crops is to include farmers in the research process of evaluating these crops prior to their commercialization. However, particularities concerning the ethical status of such research require special consideration and vigilance. For example, in such technology assessment initiatives, farmers would occupy both the roles of research participant and research investigator. Other particularities surface due to factors related to the nature of GM crops. These particularities are examined with reference to concepts drawn from the field of research ethics, namely informed consent, compensatory decisions, and issues of participant inclusion/exclusion.
\end{abstract}

Keywords: Farmers; genetically modified (GM) crops; policy; research ethics; stakeholders; strategic development; technology assessment

\section{Acknowledgements}

The authors would like to thank Dr. Beatrice Godard (Université de Montréal) for her helpful comments on a draft of this article. Behrmann was supported by fellowships from the Fonds de la recherche en santé du Québec (FRSQ), APOGEE-Net Canada, Université de Montréal, and the Social Sciences and Humanities Research Council of Canada (SSHRC). 


\section{INTRODUCTION}

The global agriculture sector has undergone numerous transformations over the past century. Innumerable advances have been made in the development of synthetic fertilizers, pesticides and herbicides, and technologically advanced machinery has significantly reduced labour-intensive cultivation practices in developed countries. Traditional forms of agriculture such as subsistence farming are now largely overshadowed by a global trend towards industrialization. ${ }^{(1, \text { p. } 375)}$ Even the major plants cultivated today have been carefully bred with the goal of enhancing traits that best suit industrial agricultural production, resulting in crops that bear little resemblance to their initial 'wild' progenitors. The Green Revolution of the late 1960s resulted in significant increases in agricultural yield and efficiency for many ${ }^{(1, p .363-365)}$ but not all regions of the globe. Many of the poorest nations remain unable to implement novel agricultural innovations due to, amongst other factors, significant resource constraints; many farmers can simply not bear the costs associated with "high tech" agriculture. ${ }^{(2)}$

A period of intense research and development, the 1960s produced a diversity of new high-yield varieties of staple crops (e.g., wheat, corn, rice) and introduced many advanced farming practices (e.g., the use of fertilizers, pesticides, irrigation). These innovations enabled many farmers (and nations) to feed the world's burgeoning population; the fact that famine remains endemic in many countries is attributable to a range of complex social, political, and economic factors (e.g., issues of international trade, agricultural subsidies and protectionism) that go beyond simple production capacity. As with so many technological innovations, the benefits derived from Green Revolution technologies were also accompanied by significant negative consequences for certain interests or stakeholders. Agriculture has become increasingly the domain of major farm corporations, to the exclusion of small family or subsistence farmers; and the associated exorbitant use of chemical fertilizers and pesticides necessary for massive monoculture practices have contributed to environmental degradation. ${ }^{(2)}$

Today, the international agriculture sector is experiencing significant pressures, in part from a growing global population and the near maximal use of arable land for food production, but also from the increasing competition made possible by globalisation. These issues have raised questions for many policy makers in developed nations about whether existing methods to improve crop varieties and farming practices are sufficient. ${ }^{(3,4)}$ Vasil, for example, has argued that "most of our major crops have reached the physiological limits of productivity...[i]t is no longer possible to significantly increase the yield in these crops by conventional breeding methods". ${ }^{(4)}$ Further, many widely used herbicides and pesticides that have greatly contributed to large yields in agricultural production are becoming ineffective in controlling pests and weeds; for example, more than 500 species of insects have developed tolerance to a wide range of common pesticides. ${ }^{(5)}$ In the context of industrial agriculture, there is arguably a pressing need for the development of technologies and strategies that can ensure food production stays in-step with global population growth (a discussion of the social, economic or political aspects of equitable global food distribution and access is beyond the scope of this paper).

One response to this challenge has been the development and application of genetically modified (GM) crops into industrial agricultural practices..$^{(4,6-8)^{*}}$ Genetic engineering technology

\footnotetext{
* Also described as a genetically modified organisms, these modifications include the removal, alteration, and addition of genes so that the newly engineered organism acquires novel attributes.
} 
entered the agricultural sector in the early 1990s, marking the beginning of an era that some have termed the 'Gene Revolution'. ${ }^{(6)}$ The first generation of GM crop varieties typically had added insect resistance or herbicide tolerance, ${ }^{(6)}$ attributes that in many contexts have significantly increased crop yield, production efficiency, farmer income, and efficacy of insect/weed management. ${ }^{(9-12)}$ These observed benefits motivated many farming communities (and nations) to embrace the technology. The cultivation of GM crops has shown near linear growth in both the developed and developing world, and they are now grown in over 20 countries. $^{(6,13,14)}$ Second generation GM crops include traits such as drought tolerance, as well as the ability to produce pharmaceuticals, vaccines, and nutrient enriched varieties of otherwise nutrient-poor staple crops. ${ }^{(6,8,15)}$

The introduction of genetic engineering into the agricultural sector has resulted in more than novel plant varieties; it has also led to significant public and policy debate around the world. The current academic and policy literatures on GM crops are still full of disagreements about the usefulness and risk to the environment and public health of these technologies. ${ }^{(7,16)}$ Not surprisingly, then, debate about the utility GM crops is highly politicized, even polarized. ${ }^{(17,18)}$ Numerous surveys also repeatedly demonstrate public resentment in many developed countries (particularly in Europe) towards the consumption of GM food products; ${ }^{(6,19-21)}$ the genetic modification of living organisms is for many people fundamentally 'unnatural' and thus unethical. $^{(22)}$ At the same time, consumers - particularly in North America - demand access to a diversity of low cost food products, regardless of the production or growing season. In this context, it is not surprising that farming in the developed and (increasingly) the developing world has become, and arguably will remain, a high tech science; and the genetic manipulation of crops is the latest tool in the arsenal of farming practices aimed at meeting the food requirements of a growing world population. However, as is case with the technological developments of the Green Revolution, it is important to note that emerging genetic engineering technology alone will unlikely result in a complete solution to the complex issue of global hunger. GM crops may be necessary, but they are not sufficient; social, political and economic transformations of national and global agriculture policies and practices are also required.

The novelty and uncertainties associated with GM technology clearly raise important questions about how developed countries are to position themselves with respect to the safe implementation of GM crops and production of GM derived food products. If the aim is to encourage agricultural advances that best serve the needs of society, how can this be done in a fashion that is both strategic (economically and politically) and publicly accountable? More to the point, how should regulators and policy makers assess this technology in order to identify and maximize its social and economic benefits, while minimizing the risks to human and environmental health, and more generally, mitigating the possibilities for social injustice and other risks to society?

This article aims to address these questions by arguing that current methods used to assess GM crops are inadequate. In developed countries, regulatory standards for the commercialization of GM crops focus too much on risk assessment; benefit assessments, if they are done at all, are too passive since they are invariably performed after product commercialization. Furthermore, such assessment procedures are exclusively technocratic in nature and do not assess broader social, political and cultural dimensions of agriculture. Current 
assessment processes are thus inadequate for the strategic development of GM crops. A solution to the above weaknesses, it will be argued, resides in the greater inclusion of farmers (a key stakeholder group) into research and assessment procedures of agricultural innovations. Indeed, there is a growing recognition - or at least a public discourse - among many policy makers and academics about the importance and utility of including various stakeholder groups in policy development; the idea is that if diverse public voices or perspectives are "at the table", then this will lead to better (i.e., more representative, equitable, and publicly acceptable) policy. ${ }^{(23,24)}$ Overall, we argue that the strategic development of GM crops entails moving beyond the traditional reliance on techno-scientific analyses of risk and benefit, to a more fully integrated reflection on the range of farmer interests and values at stake in contemporary agriculture. ${ }^{(25)}$

However, if farmers are empowered and integrated in the assessment and development of GM crops, what principles should be followed to ensure that this process is ethical? Instead of drawing on the tools of deliberative democracy (e.g., public consultation, questions of representation) that have been used widely in this and other related contexts, we will refer to the academic literature and international standards in research ethics, specifically that which regards the involvement of human subjects in investigative research. We argue that attention to issues of informed consent, compensatory decisions, and the equitable inclusion or exclusion of participants can help clarify and better structure the ethical responsibilities of the various stakeholders involved in the assessment and strategic development of new agricultural technologies.

\section{DISCUSSION}

\section{A. Current Assessment Processes for GM crops: Risks and Benefits}

Unlike novel plant varieties produced via more traditional methods (such as by cross breeding and the formation of hybrid species), international regulatory standards require that GM crops undergo a series of field trial assessments prior to their commercialization. ${ }^{(26,27)}$ This specific regulatory oversight of GM crops exists because certain GM cultivating nations have acknowledged that plant varieties produced by genetic engineering carry a greater potential risk to the environment and public health. Canada is an exception, where equivalent regulatory standards are applied to any new plant variety, regardless of whether it is developed through genetic engineering or other traditional plant breeding methods. ${ }^{(26)}$

Field trial experiments for GM crops typically proceed through three stepwise phases. ${ }^{(26,}$ 27) At each phase, the crop is assessed for potential environmental risk factors. Typical factors assessed include the potential for the GM crop to become a weed (i.e., a problematic plant species); the ability of the crop to transfer the genetic modification to other organisms; the stability/inheritability of the genetic modification; potential pathogenicity to other organisms; and whether the GM crop has the potential to produce environmental toxins. The initial field trial phase involves cultivating the crop in an enclosed greenhouse, isolated from the exterior environment. In the second phase, the GM crop is cultivated in open fields that are (in principle) isolated from other farm plots. Products from these field trials are subsequently disposed of and do not reach the market for human or animal consumption. ${ }^{\dagger}$ The last phase involves cultivating the GM crop in large unconfined fields. Once successfully through the environmental risk

\footnotetext{
${ }^{\dagger}$ A notable exception was the inadvertent and highly publicised detection of Starlink Bt corn in Taco Bell taco shells; this GM corn had only been approved for use in animal feed.
} 
assessment, the crop is labelled as being low risk to the environment and thus can be commercialized for agriculture production. Regulatory oversight continues postcommercialization in order to identify whether environmental problems arise from the broad cultivation of the GM crop. Aside from field trial environmental impact studies, GM crops also undergo assessments that focus on identifying risks to human health. ${ }^{(26,27)}$ These assessments $^{2}$ typically focus on whether the genetic manipulation of the crop produces unpredictable alterations in biochemical composition, alters its nutritional quality, or introduces novel toxins or allergens. Government regulatory oversight of GM crops is thus technocratic and primarily aimed at assessing whether novel plant varieties possess significant risks to human health or to the environment.

But what about factors that fall outside the classification of risks? How are the benefits of GM crops assessed? Currently, it is mainly academic researchers who perform benefit assessments of these crops. As previously mentioned, the first generation and most widely cultivated GM crops have the added genetic traits of herbicide tolerance or insect resistance, traits that can simplify weed and pest management strategies by reducing the need for large scale application of chemical pesticides or herbicides. ${ }^{(28,29)}$ Post-commercialization research has focussed on the impact on pesticide and herbicide usage, studies which essentially confirm

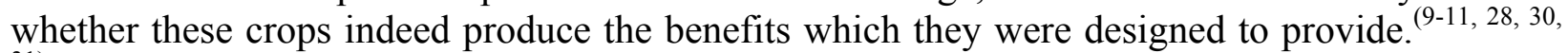
31)

Many studies have also addressed the question of whether the cultivation of GM crops possess economic advantages in comparison to the cultivation of non-GM varieties. That is, they examine the 'obvious' economic benefit to farmers - why would farmers embrace this technology if it could not provide significant economic gains? ${ }^{(13)}$ Indeed, some economic analyses have demonstrated that cultivation of GM crops can increase production yields and decrease the use of chemical pesticides and herbicides. ${ }^{(9-11,30,31)}$ Interestingly, these studies, which focussed on affirming obvious benefits, have also identified additional benefits that were not inherently predictable with herbicide tolerant and insect resistant GM crops. Many of these benefits are social, health, and environment related, some of which will be described briefly.

In the context of social factors, better pest and weed management from GM crops can reduce farmer stress and allow for more efficient work habits. ${ }^{(31)}$ The ability for farmers to better control pest infestations with insect resistant varieties can minimize the risks of crop loss due to unpredictable fluctuations in insect infestations. This reduced risk has meant that some farmers are less concerned about the success of their harvests; in other words, the farmer can gain a "greater peace of mind". (10) This is particularly significant in certain regions of the world where stress originating from insect infestations is a leading cause of farmer suicide. ${ }^{(10)}$ In relation to herbicide tolerant crops, the ability to apply only one herbicide to control weeds has translated into decreased workload and time savings. This provides farmers with more time, flexibility, and resources to focus on the cultivation of other crops. ${ }^{(31)}$

With regards to health factors, the adoption of insect resistant GM crops in certain regions of the world has reduced the incidence of farmer poisoning due to the heavy use of toxic farm chemicals. ${ }^{(9)}$ For example, many cotton farmers in China apply pesticides manually and without protective clothing; the introduction of insect resistant GM cotton has sharply reduced chemical pesticide applications, and thus, toxic exposures to these compounds. In the context of 
environmental factors, the decreased need to apply herbicides and pesticides with GM crops can reduce the use of machinery that applies these chemicals. Aside from the environmental gains of using fewer chemicals, the decreased use of farm machinery can lower gasoline consumption and thus decrease air pollution and green house gas emissions. ${ }^{(10,28)}$

To summarise, assessments performed on GM crops after their commercialization typically demonstrate their obvious utility in farming practice, such as reductions in pesticide and herbicide use and the potential for economic advantages. However, these assessments also uncover unexpected potential benefits that were not inherent in the initial proposition or justification for this technology. That is, there are non-obvious social, health, and environmental benefits that can arise with the use of GM crops. It is important to bear in mind, however, that farmers around the world do not share these benefits uniformly or consistently.

\section{B. Inclusion of farmers in the assessment of GM-crops}

The current technocratic approach to technology assessment of GM crops - with its focus on identifying risks and only post-commercialization examination of potential benefits - raises important questions. First, do current methodologies promote strategic technology development? And do they adequately address the needs of farming communities and empower farmers in the development of their industry?

It is our contention that current assessment procedures for GM crops are not conducive to strategic technology development. In order for policy makers to make decisions on how to strategically subsidize and encourage the broad distribution of promising technologies, they must be provided with detailed information concerning utility, benefits and risks prior to the technology's commercialization. ${ }^{(32)}$ Regulatory risk assessments fail in this regard for they focus exclusively on risks, while the identification of obvious (i.e., economic) benefits are passively assessed after the commercialization of crop varieties. Furthermore, certain weaknesses are observable only after the GM crop has been cultivated within a 'real-world' setting. Such an approach is generally not conducive to sustainable development efforts, and is likely short sighted with respect to ethical and social concerns. A better strategy for technology assessment and eventual adoption is to base decisions on more well rounded perceptions of potential social benefit that include social and ethical considerations. ${ }^{(32)}$ Yet in relation to GM crops, which societal group is best suited to address and define the benefits, risks, and the socio-ethical concerns associated with this technology? Obviously, consumers and environmental interest groups are important stakeholders, and they have been key vocal participants in discussions about and analyses of GM crops. But another key and often neglected group is the people who will actually implement the technology in question, namely farmers.

So far, our discussion of GM crops has focused largely on the potential benefits for farmers; but as with other agricultural developments (e.g., monoculture, automation), the use of GM crops also has the potential to harm certain farming communities. To begin with, the introduction of novel technologies in global agricultural systems is often associated with injustices and the absence of sustainable development. ${ }^{(33)}$ Despite consistent improvements in the efficiency and productivity of agriculture, new capabilities do not benefit the poorest nations nor the small-scale farmer. Technological advances seem invariably to be best suited to large industrial farms in developed and developing countries, and GM crops are no exception. For example, Hall and colleagues ${ }^{(34)}$ demonstrate that the introduction of herbicide tolerant crops into 
Brazilian agriculture has almost exclusively been of economic benefit to industrial farms. These crop varieties have remained out of reach of small-scale subsistence farmers due to their poor resource capacities (e.g., inability to pay high seed costs) and marginalized status. The ability of industrial farmers to acquire GM crop technologies has had the effect of furthering the social exclusion and economic depravation of small subsistence farmers in Brazil. ${ }^{(34)}$

Another risk to certain farm communities stemming from the cultivation of GM crops relates to unforeseen complexities in the management of weeds and insects. Exclusive reliance on and excessive use of a given pesticide raises the possibility for the development of pestresistant weeds and insects. In relation to GM crop farming, the exclusive use of the herbicide glyphosate for weed management in the cultivation glyphosate-tolerant GM-crops has resulted in the evolution of glyphosate-tolerant weeds in the United States. ${ }^{(35)}$ This in turn has inhibited farmers' abilities to effectively manage weed infestations with resultant economic losses.

A final example of unexpected GM crop risks that have harmed specific farm communities pertains to over-estimated yield gains expected from a given genetic modification. The cultivation of Bt-cotton in India is exemplary. ${ }^{(36)}$ The introduction of insect-resistant Btcotton was encouraged by Indian policy makers due to promised increases in yield from reductions in pest-related losses. However, mass cultivation within a 'real-world' setting has resulted in minimal yield gains since multiple environmental factors have apparently neutralized any gains expected from better pest management. Overall, the broad cultivation of Bt-cotton has demonstrated "the fact that yields are much more complex in reality than a linear function of one technology". ${ }^{(36)}$ In turn, mass cultivation of Bt-cotton within certain Indian farming communities has put 'all their eggs in one basket', and thus diverted limited resources away from more economically stable practices such as diversifying agricultural production capacities.

What actions could be taken to reverse or mitigate such social inequities in the agricultural sector, and how can real-world problems such as herbicide resistance and discrepancies in expected yield gains be more readily identified? For a start, policy makers might preferentially support and promote the commercialization of innovations that are likely to be of equal benefit to all members of the farming community, and not just for large-scale industrial farms. This would entail consideration of how a particular innovation would be taken up by different types of farmers (small and/or subsistence vs. large scale), the economic costs of purchasing the innovation (is it affordable for all farmers?), and how it could be best integrated (or not) into existing farming practices. With this knowledge, policy makers might then consider implementing appropriate social safety mechanisms to counter any likely injustices (e.g., by providing subsidies to some farmers to purchase the innovation).

But how are policy makers to evaluate whether a given technology can benefit farmers equally? And conversely, how can the potential for harm be assessed for all population segments of an increasingly globalised agricultural industry? One possible solution is to empower farmers and integrate them in the process of developing and assessing emerging agriculture technologies. This system would improve on current assessment methodology by moving beyond government and corporate-sponsored research that focuses on assessing the obvious benefits and potential risks of the GM crop to the exclusion of broader social and cultural farming practices that are equally important in evaluating the merits and legitimacy of emerging agricultural technologies. 
Overall, in order for the development of agricultural innovations to be strategic and publicly acceptable, technology assessments must move beyond a narrow technocratic process. That is, policy makers should - whether through their own analyses, or through more direct farmercentred consultations - pay particular attention to the social, economic and moral values at stake related to the future commercialization and broad implementation of GM crop varieties.

\section{Ethical Principles and Challenges with Farmer Participation in GM Crop Research}

Including farmers as key stakeholders in pre-commercialization technology assessments - similar to what has been suggested for improving health technology assessment ${ }^{(37,38)}$ - may be an effective means to identify the obvious benefits of an innovation, as well as the non-obvious benefits and potential risks that farmers should expect from the introduction of novel GM-crop varieties. Nonetheless, it is important to also consider ethical principles and specific challenges associated with such a process. Specifically, for our purposes the issues of primary interest are those concerning informed consent, compensation, and the inclusion of various farmer populations in research initiatives. As we will demonstrate, assessing these ethical issues is important for several reasons. At the most general level, attention to these ethical principles and the challenges facing farmers - highlights the fact that farmers are, and should be treated as, active participants in the research and technology development process. To not attend to these principles is to reinforce a view of farmers as passive recipients of technology, unable to question the utility or appropriateness of a particular innovation. Such a paternalistic view has largely been rejected in the health field - patients and research 'subjects' are now increasingly recognised as active collaborators in healthcare choices and 'participants' in the research process. By analogy, in the agricultural context, the concept of empowering farmers - something that is widespread both in agricultural policy and commercial messages - is meaningless if one does not also attend to principles of autonomy, informed consent, and participation in the research process.

In practice, farmers can and often do participate in corporate-sponsored agricultural research, where their autonomous consent to conduct assessments is certified through a contract agreement. However, such methodology does not taken into account the major power imbalance between agrobiotech or seed companies and farmers; the potential for active participation based on a "fully informed consent" will be significantly limited, when compared to non-industry funded or more open agricultural (e.g., academic) research. As is the case in the conduct of clinical trials for development of novel medicines, there is a world of difference between pharmaceutical industry-sponsored research where the company sets the agenda and the "rules of the game", and academic/university research where researchers are able to define and re-define a line of inquiry, and even include patients as active participants or collaborators. These differences are similar to our proposed model for GM assessment that includes farmers as active participants and collaborators in the research process, versus other models such as farmers conducting corporate sponsored research that are strictly defined by contract agreements.

\section{Specific considerations related to informed consent}

One prime ethical criterion for including human participants in investigative research is that these individuals make the autonomous decision to participate, i.e., that they are capable of providing informed consent to the proposed investigation. (39, para. 13, ${ }^{22)}$ According to international guidelines, such as those in the Declaration of Helsinki, ${ }^{(39)}$ several characteristics and factors of 
the proposed experimentation must be made clear to the potential participant in order to enable informed consent. For one, the relevant hypothesis of the research needs to be stated. Secondly, depending on the hypothesis of the research, the participant should stand to benefit (even if only indirectly) from the potential results of the research endeavour. Lastly, any predictable risks pertaining to the investigation must be made clear and these risks should not outweigh the potential benefits (e.g., to the individual, their group or society). These standards were developed with attention to biomedical research, thus it is important to examine the particularities or differences if these standards are placed in the context of farmer participation in research aiming to assess GM crops.

Information concerning the hypothesis, risks, and benefits for farmer assessments of GM crops will indeed be particular. This stems from the rather unique nature of the research to be performed. In much of biomedical research, the research participant is a patient subjected to specific diagnostics or experimental interventions (e.g., drugs or other medical treatments) - they may be more or less actively involved in the study, but they are rarely active in conducting the research itself. In other words, not withstanding the current preference in the research ethics literature for the more empowering language of participation, patients through their bodies are subjected to or are the subject of research; more participatory research nonetheless occurs, particular in the context of studies involving rare diseases and the development of some biotechnological therapeutics. By contrast, in the study of GM-crops, farmers might be thought in some cases to be both the subject of research (alongside the GM-crop) and one of the principle researchers.

Agricultural assessment research seeks to determine the utility, safety, etc. of a crop, for farmers as participants (e.g., its risks and benefits), and this necessitates that they agree to plant the crop in their fields and then document the benefits and risks associated with this product during the crop lifecycle. In a sense, then, agricultural technology assessment research involves a participant (farmer $=$ patient) testing an intervention $(\mathrm{GM}$ crop $=$ medical treatment $)$ in their field (farm = patient's body), and also study the effectiveness and obvious/non-obvious benefits of the crop (farmer $=$ researcher or just patient reporting?). Unlike biomedical research, in which patients rarely benefit directly (e.g., they may be part of a randomized control trial, be on a placebo arm) farmers more often stand to benefit directly from participation (e.g., they are usually paid to participate; discussed in the following section) and at the same time may also incur substantial economic or environmental risks (e.g., crop failure, development of herbicide tolerant weeds). Given these particularities, how then should farmers be informed in order to be able to freely consent to participate in GM crop assessment research?

For one, as with biomedical research, it is often technically impractical to provide farmers with detailed descriptions of hypothesis, risk, and benefit due to the nature of the research being proposed; this information has to be synthesised and made accessible to nonscientists. In terms of the hypothesis, GM crop developers can provide limited predictions on the obvious benefits to be expected from the future cultivation of these crops. However, farmer's assessments might also identify 'non-obvious' benefits and risks associated with the technology. In all, detailed predictable benefits accruing from farmer participation in assessment initiatives are unknown because benefits are one of the key factors to be identified by research participants; and the same situation exists for risks. Ill defined risks and benefits related to GM crop 
assessment raise questions of whether sufficient information can actually be provided to enable farmers to clearly consent to participate in such research. Specific ethical attention will need to be given to exactly how informed farmers are during recruitment, to ensure fully autonomous participation in GM crop assessments.

When conducting investigative research involving human beings, researchers ought to evaluate the informed consent from a wider perspective that includes the ideologies of the community in which the research participant is a member. Brody and colleagues, for example, note that the informed consent of an individual does not necessarily reflect the collective interests or consent of the community where the research is planned to be conducted. ${ }^{(40)}$ When evaluating the ethical status of research initiatives, it is essential to consider whether the research could expose the community to collective risks. ${ }^{(40)}$ These notions of potential conflict between individual and community consent (and interests) require particular vigilance with farmer assessments of GM crops.

The cultivation of GM crops carries potential collective risks to farming communities, especially with regards to the 'co-existence' of GM and non-GM crops. ${ }^{(41)}$ Discussions pertaining to the co-existence of these crops highlight the difficulties that can be encountered when agricultural systems must prevent the contamination of non-GM produce by GM crops. In order to prevent the intermixing or cross-contamination of GM and non-GM species, agricultural systems typically need to develop separate infrastructure for each class of product. This is of particular importance in regions where organic farming is practiced. ${ }^{(41)}$ Certified organic produce regulations may set strict limits on the permitted presence of GM crops in the organic harvest as a criterion for acceptability for the organic food market. If an organic harvest is identified to contain evident contamination by GM crops, the harvest will be excluded, an obvious significant risk for organic farming communities. Additionally, many of these communities are either disinterested or unable to develop the separate infrastructure needed to prevent possible contamination. Thus, many organic farming communities collectively agree not to cultivate GM crops and even lobby against the introduction of GM crops in neighbouring farms. Thus, despite the informed consent of an individual farmer to participate in GM crop assessment initiatives, performing such research in organic farming regions could arguably be considered unethical because of the substantial collective risk it may pose for the broader agricultural community.

\section{Complexities with compensation}

Another issue requiring close scrutiny is how to structure compensation schemes for farmers that participate in GM crop research. As already mentioned, in most biomedical research (and in human subjects research in the social sciences), it is rare that participants are paid to be involved because of the ethical concern that payment would constitute undue influence or inducement and thus negate the autonomous choice to participate. ${ }^{(42):}$ To perform such research, farmers will need to devote a portion of their agricultural land to experimental cultivation. Since it is proposed that farmers intervene in the assessment of these crops prior to their official

\footnotetext{
* An exception to this rule against payment is the involvement of healthy participants in Phase 1 clinical trials of pharmaceutical drugs, where the goal is to test toxicity and not benefit. In this case, the rationale for payment is that these healthy participants are subject to often substantial risk, with no possibility of direct benefits. In contrast, patients who are enrolled in Phase 2, 3 or 4 of clinical trials are not paid for their involvement, because there is arguably at least the possibility that they can benefit directly (or indirectly, as a member of a patient/disease group).
} 
commercialization, the produce from the cultivation of experimental GM crops will need to be disposed of and will not be marketed for consumption. Therefore, farmers will need to be compensated for any lost production that may accrue from participating in GM crop research. They will also need to be compensated for the time and resources they devote towards assessing novel GM crops. However, decisions on how to compensate farmers may be more complicated than initially predicted.

First, the crops typically cultivated by a farmer may raise problems of injustice. Consider the hypothetical situation of a farmer who has the capabilities to cultivate an expensive cash-crop that has a high market value (e.g., coffee) and a neighbouring farmer who cultivates a low market value staple crop (e.g., potatoes). If both farmers sacrifice an equal proportion of land for GM crop assessments, the farmer cultivating the cash-crop will have lost more potential profit than will the farmer cultivating the staple crop. Therefore, it might be thought that one farmer should receive more compensation for participating in research. But would that be fair? Both farmers perform equivalent research activities, so monetary compensation for this activity ought to be equivalent. As a comparison, one would not expect to provide more compensation to individuals with high salaries, versus individuals with minimum wage jobs, who sacrifice work hours to participate in clinical drug trials. ${ }^{\S}$

One method to avoid this injustice is to compensate all farmers with equally generous amounts of compensation. However, this method raises the possibility of undue inducement, mentioned above. ${ }^{(43)}$ Large compensation factors can provide incentive for people to participate in research they would otherwise avoid. In the previously described hypothetical situation, the possibility for undue inducement is more likely with the staple-crop farmer relative to the cashcrop farmer; or between the large scale and small scale farmer. In summary, differences in the crops cultivated by farmers (or their scale of farming operation) prior to participation in GM crop assessments can complicate decisions on how to distribute compensation ethically.

Second, unique complexities related to compensation can arise from the fact that farmers assessing GM crops in their fields will be, as discussed in the previous section on informed consent, participating in this research as both a human participant and as a researcher. With the proposition that farmers are to identify and document potential problems and benefits with the cultivation of experimental GM crops, they occupy a position as an active researcher. This role has a vastly different set of responsibilities and tasks to that of daily farming practice. Farmers participating in GM crop assessments thus arguably acquire an additional job title - that of researcher - and thus ought to be appropriately remunerated during their involvement in the assessment process. This then also raises concerns about conflict of interest (similar to those for clinician-researchers ${ }^{(44)}$ ), as farmers might have a not insignificant financial interest in seeing their assessment produce positive results. Thus, the inclusion of farmers in assessment procedures requires specific debate about what should constitute appropriate compensation for

\footnotetext{
${ }^{\S}$ For a discussion of different models of compensation for participants in research, see Dickert, N. and Grady, C., What's the Price of a Research Subject? Approaches to Payment for Research Participation, New England Journal of Medicine, 1999, 341:198-203; Pentz, R. D., Spreading It Around: Money for Researchers and Research Participants, The Mount Sinai Journal of Medicine, 2004, 71 (4): 266-270
} 
the cultivation of experimental GM crops, with regards to recompense for the labour involved, lost opportunity costs and risks undertaken.

\section{Inclusion and exclusion of farmer populations}

Another key factor for conducting ethical research is that the experimental population be determined on the principle of inclusion, in order to ensure a just sharing of the benefits and burdens of research. ${ }^{(40)}$ In other words, the composition of research participants should not favour a particular social group, with the concomitant exclusion of other members of the population. While the principle of inclusion appears rather straightforward, marginalized individuals and members of vulnerable communities are often still excluded from research, "for their benefit" or protection, because their abilities to autonomously consent to participate in research are compromised or unattainable. ${ }^{(45)}$ Notable examples of exclusion in medical research have included the exclusion of women, children, the elderly or members of visible minority groups. While members of these groups have been historically subject to unethical experiments and thus are due special protection, exclusion from "risky" research entails that they cannot benefit from the results of research, e.g., in terms of access to medications or availability of information that may be specific to their particular needs or social circumstance. ${ }^{(46,47)}$

Given this background, how does the principle of inclusion and the potential problem of exclusion relate to farmers? To begin with, the heterogeneity of farmers requires clarification. Farming populations can differ by factors such as geographical location, farming practices (e.g., organic or conventional cultivation), and the degree of agricultural industrialization (e.g., subsistence farming versus large-scale industrial farming). In terms of geographical location, efforts ought to be made to ensure that isolated farming communities (whether in developed or developing countries) are not excluded from research opportunities. To expand, isolated communities can have fewer resources, technological capacities, necessary infrastructure, and visibility to GM crop developers. All these factors contribute to the marginalization of these farming communities. Though marginalized, the need for better farming practices in these communities should not be viewed as less important than those of more fortunate farming communities. It will be impossible for locally relevant GM crops to be developed if the communities in which they are to be used are not involved; there are obviously important differences between the types of crops to be grown in North America and Europe, and in Latin America or Asia. Therefore, vigilance is needed to ensure that different regions as well as isolated farming communities have equal opportunities to participate in the assessment of experimental GM crops. One notable example to address this issue may be the significant expansion of GM crop research in developing countries - particularly in Africa and Asia - that specifically focuses on locally relevant crops.

In terms of farming practices, organic farmers would likely be excluded from GM crop assessments due to the unwanted possibility for contamination of their organic produce. ${ }^{(41)}$ However, this exclusion may be ethically justified since organic farmers would likely make the autonomous decision to avoid the presence of GM crops near their organic cultivators, and thus, voluntarily not participate in these research opportunities. Yet, the voluntary exclusion of organic farmers may still create problems of injustice. This relates back to the discussion of compensation of farmers for GM crop assessments. It might be unjust to automatically exclude 
organic farmers from participating in research to assess emerging GM technologies and receive monetary compensation for this activity.

Another concern with regards to just inclusion in research is the degree of agricultural industrialization. Efforts should be made to ensure that research assessment of experimental GM crops includes small-scale and subsistence farmers as well as large-scale industrial farmers. Inclusion of farmers from both small and large-scale operations will identify whether one class will stand to receive greater benefit from the future adoption of these GM crops (e.g., the social exclusion of subsistence farmers in Brazil associated with that country's introduction of GM soy $\left.{ }^{(34)}\right)$. Of related concern is the extent to which particular farmer groups may constitute vulnerable populations, and thus as has been common in biomedical research, ${ }^{(46,47)}$ be excluded from participating in research because they are illiterate and/or socio-economically deprived and thus have reduced autonomous decision making capabilities. ${ }^{(34)}$ Given the likely vulnerable status of subsistence farmers, it is particularly important to consider whether they would ever be able to provide informed consent to participate in assessments of GM crops. Further, since farmers may occupy the role of both research participant and researcher, the illiterate status of many subsistence farmers will likely make this group incapable of performing detailed technology assessments. It might nonetheless be possible to build in protective measures to support this vulnerable group and enable participation in research (e.g., as is done for children or incompetent adults in biomedical research), but this will require considerable and detailed ethical reflection.

\section{CONCLUSION}

The global agriculture sector has witnessed countless technological advances over the past century. Technological progress has transformed farming into a high-technology industry and is largely credited with keeping agricultural production in-step with the growing global population needs, even though it has not solved the underlying factors related to global hunger. Current commercialized GM crops have been observed to provide benefits in the form of better pest and weed management and higher production yields; the hope is that these crops can provide benefits beyond that of farming practices, to also include social, health and environmental benefits. However, the introduction of GM crops into farming systems also carriers certain risks, namely that these crops can favour industrial farming practices that further marginalize small-scale subsistence or organic farmers. It is thus important that appropriate technology assessment procedures be implemented to maximise the benefits of this emerging agriculture technology and minimize its risks.

In this article, we have argued that existing methods to assess GM crops do not promote the strategic development and equitable distribution of promising innovations. Government regulatory oversight of this technology focuses too exclusively on risk assessments and provides little information on associated potential benefits. One method to promote the strategic development of GM crops - in line with moves towards broader public participation in policy making - is the inclusion of farmers in the assessment and development processes, prior to commercialization. Early assessments of experimental GM crops by farmers can identify issues pertaining to whether both small and large-scale farmers stand to benefit from the technology. Farmer assessments can provide policy makers with the information needed to enact policies that promote the development and efficient and equitable introduction of GM crops. But empowering 
farmers through their participation in the technology assessment process also raises important ethical concerns, particularly with regards to the ethical participation in the research process.

Drawing on concepts developed in the field of research ethics, we show that it is important to attend to both the similarities with biomedical research (e.g., the need to obtain informed consent, protect research participants, and evaluate the balance of harms and benefits of research) but also to the differences that arise in the context of agricultural research. In particular, it is important to note that farmers may occupy the dual roles of research participant and researcher in technology assessment initiatives. This issue is important because it has an impact on free and informed consent (what information is sufficient, in what contexts?), and the determination of reasonable and fair compensation for participation (should farmers be compensated like patients or healthy volunteers in clinical research, or as researchers?), it highlights the potential for significant conflicts of interest, and it raises concerns about the equitable inclusion of vulnerable groups (e.g., small-scale subsistence farmers, organic farmers) in the research process. Attention to these concerns, we believe, can help clarify and better structure the ethical responsibilities of the various stakeholders (policy makers, farmers, researchers) involved in the assessment and strategic development of new agricultural technologies. 


\section{REFERENCES}

1. Knox PL, Marston SA, Nash AE. Human geography: Places and regions in global context. Canadian Edition ed. Toronto: Pearson, Prentice Hall; 2004.

2. Evenson RE, Gollin D. Assessing the Impact of the Green Revolution, 1960 to 2000. Science. 2003 May 2, 2003;300(5620):758-62.

3. Huang J, Pray C, Rozelle S. Enhancing the crops to feed the poor. Nature. 2002;418:67884.

4. Vasil IK. The science and politics of plant biotechnology--a personal perspective Nature Biotechnology. 2003;21:849-51.

5. Moberg WK, editor. Managing Resistance to Agriochemicals. Washington, USA: ACS Symposium Series; 1990.

6. The State of Food And Agriculture 2003-04: Food and Agriculture Organization of the United Nations2004.

7. McGloughlin M. Ten reasons why biotechnology will be important to the developing world. AgBioForum. 1999;2:163-74.

8. Cohen JI. Poorer nations turn to publicly developed GM crops. Nature Biotechnology. 2005 2005;23:27-33.

9. Pray CE, Huang J, Hu R, Rozelle S. Five years of Bt cotton in China -- the benefits continue. The Plant Journal. 2002;31:423-30.

10. Edge JM, Benedict JH, Carroll JP, Reding HK. Bollgard Cotton: An Assessment of Global Economic, Environmental, and Social Benefits. The Journal of Cotton Science. 2001;5:121-36.

11. Qaim M, Cap EJ, de Janvry A. Agronomics and Sustainability of Transgenic Cotton in Argentina. AgBioForum. 2003;6:41-7.

12. Qaim M, Traxler G. Roundup Ready soybeans in Argentina: farm level and aggregate welfare effects. Agricultural Economics. 2005;32:73-86.

13. Up from the dead. The Economist. 2006 May 6th, 2006:63-6.

14. James C. Preview: Global Status of Commercialized Biotech/GM Crops: 2004. ISAAA Briefs. 2004;32:1-12.

15. Potrykus I. Golden rice and beyond. Plant Physiology. 2001;125:1157-61.

16. Altieri MA, Rosset P. Ten reasons why biotechnoology will not ensure food security, protect the environment and reduce poverty in the developing world. AgBioForum. 1999;2:15562.

17. Millstone E. Analysing biotechnology's traumas. New Genetics and Society. 2000;19:117-32.

18. Another inconvenient truth. Nat Biotech. 2007;25(12):1330-.

19. Knight AJ. Does Application Matter? An Examination of Public Perception of Agricultural Biotechnology Applications. AgBioForum. 2006;9:121-8.

20. Food Biotechnology: A Study of U.S. Consumer Attitudinal Trends 2006 REPORT: International Food Information Council2006.

21. Bennett DJ, Abrams M, E. BJ, al. e. Ethical aspects of agricultural bitechnology. The Hague: EFB Task Group on Public Perceptions of Biotechnology1999.

22. Ryan A, Burke D, Gale M, Heap B, Leith P, Hill J, et al. Genetically modified crops: the ethical and social issues. London: Nuffield Council on Bioethics1999.

23. Wynne B. Creating public alienation: Expert cultures of risk and ethics on GMOs. Science as Culture. 2001;10(4):445-81. 
24. Montpetit E, Rouillard C. Culture and the democratization of risk management: The widening biotechnology gap between Canada and France. Administration Society. 2008;39(8):907-30.

25. Williams-Jones B, Doizé B. Managing Antimicrobial Resistance in Food Production: Conflicts of Interest and Politics in the Development of Public Health Policy. Les ateliers de l'éthique. In press 2010.

26. MacKenzie DJ. International Comparison of Regulatory Frameworks for Food Products of Biotechnology. In: Committee CBA, editor. Agriculture and Biotechnology Strategies (Canada) Inc: Agriculture and Biotechnology Strategies (Canada) Inc.; 2000. p. 1-62.

27. Flint J, Gil, L., Verastegui, J., Irarrazabal, C., Dellacha, J. Biosafety information management systems. A comparative analysis of the regulatory systems in Canada, Argentina, and Chile. Electronic Journal of Biotechnology. 2000;3:9-29.

28. Phipps RH, Park JR. Environmental Benefits of Genetically Modified Crops: Global and European Perspectives on Their Ability to Reduce Pesticide Use. Journal of Animal and Feed Sciences. 2002;11:1-18.

29. Sharma HC, Ortiz R. Transgenics, pest management, and the environment. Current Science. 2000;79:421-37.

30. Fulton M, Keyowski L. The producer benefits of herbicide-resistant canola. AgBioForum. 1999;2:85-93.

31. Marra MC, Pardey PG, Alston JM. The payoffs to agricultural biotechnology: an assessment of the evidence. Washington D.C.: Environment and Production Technology Division, International Food Policy Research Institute2002.

32. Lehoux P, Williams-Jones B. Mapping the integration of social and ethical issues in health technology assessment. Int J Technol Assess Health Care. 2007 Winter;23(1):9-16.

33. Pellerin D. Abstract [Evaluation of the sustainability of Quebec agriculture production systems] 4th Conference on Research and Innovation in Quebec Agriculture and Agri-Food. 2007; Quebec city.

34. Hall J, Matos S, Langford CH. Social Exclusion and Transgenic Technology: The Case of Brazilian Agriculture. Journal of Business Ethics. 2008.

35. Lemaux PG. Genetically Engineered Plants and Foods: A Scientist's Analysis of the Issues (Part II). Annual Review of Plant Biology. 2009;60:511-59.

36. Kuruganti K. Bt Cotton and the Myth of Enhanced Yields. Economic \& Political Weekly. 2009;44:22-9.

37. Lehoux P. The problem of health technology: Policy implications for modern health care systems. New York: Routledge; 2006.

38. Lehoux P, Williams-Jones B. Mapping the integration of social and ethical issues in health technology assessment. International journal of technology assessment in health care. 2007;23(01):9-16.

39. Weed DL. Precaution, Prevention, and Public Health Ethics. Journal of Medicine and Philosophy. 2004;29(3):313-32.

40. Brody B, McCullough LB, Sharp RR. Consensus and Controversry in Clinical Research Ethics. JAMA. 2005;294(11):411-1414.

41. Brookes G, editor. Co-existence of GM and non GM crops: current experience and key principles2004; Dorchester, UK. 
42. Corrigan OP, Williams-Jones B. Pharmacogenetics: The bioethical problem of DNA investment banking. Studies in History and Philosophy of Science Part C: Studies in History and Philosophy of Biological and Biomedical Sciences. 2006;37(3):549-64.

43. Hawkins JS, Emmanuel EJ. Clarifying confusions about coercicion. Hastings Center Report 2005;35(5):16-9.

44. Schafer A. Biomedical conflicts of interest: a defence of the sequestration thesis-learning from the cases of Nancy Olivieri and David Healy. Journal of Medical Ethics. 2004;30(1):8-24.

45. Ameisen J-C. Avenir de la recherche : enjeux éthiques. 2005; Available from: http://www.espace-ethique.org/fr/actualite.php.

46. Rhodes R. Rethinking Research Ethics. AJOB. 2005;5(1):7-28.

47. Beauchamp T. How Not to Rethink Research Ethics. AJOB. 2005;5(1):31-3. 